\title{
Fitting contraceptive diaphragms: Can laywomen provide quality training for doctors?
}

Sally Pickard MBBS, BSc, DRCOG, Staff Grade; Paula Baraitser MBBS, BSc, MA, MFFP, Senior Clinical Medical Officer, Department of Reproductive Health, Community Health South London, NHS Trust, UK; Mary Herns, PhD, MSc, BSc (Hons), SRN, Education Adviser, GKT Schools of Medicine, London, UK; Helen Massil, MRCOG, MFFP, Director/Consultant, Department of Reproductive Health, Community Health South London, NHS Trust, UK

Correspondence: Sally Pickard, Department of Reproductive Health, Community Health South London NHS Trust, St Giles Road, London SE5 7RN, UK .

(Accepted $12^{\text {th }}$ March 2001)

The Journal of Family Planning and Reproductive Health Care 2001: 27(3): 131-134

\begin{abstract}
Objective. To test the feasibility of training laywomen as professional patients to teach doctors to fit the contraceptive diaphragm.

Design. Semi-structured interviews with instructing doctors and questionnaires to DFFP trainees. These documented current teaching practice and the acceptability of professional patients. The Delphi technique was used to establish a curriculum for the professional patients, training programme.

Results. The results show that there is currently a lack of standardisation in teaching methods and content with respect to diaphragm fitting. All instructing doctors and DFFP trainees involved had experienced difficulties in recruiting women for training, and the majority would be happy to work with professional patients. After three rounds of the Delphi procedure, consensus was reached and a curriculum developed. Five women were recruited on to a training programme, and four successfully completed it.

Conclusion. Lack of standardisation and difficulty recruiting patients are current problems when training doctors to fit diaphragms. Our study shows that the use of professional patients would be acceptable to both DFFP trainees and instructing doctors, and that it is possible to recruit and train women for this purpose.
\end{abstract}

\section{Key message points}

- Professional patients are laymen and women who are trained to teach history and examination skills to doctors by role-playing patients.

- DFFP trainees are willing to learn from and be assessed by professional patients.

- The employment of professional patients to teach diaphragm-fitting provides an opportunity for trainees to obtain feedback on their examination skills from a patient's perspective.

\section{Introduction}

The training programme for the Diploma of the Faculty of Family Planning (DFFP) aims to ensure that doctors are competent to provide all contraceptive methods. The contraceptive diaphragm is an important family planning option, particularly for those spacing their families, or for whom other methods are unsuitable or unacceptable. ${ }^{1}$

Diaphragm-fitting requires technical and communication skills, some of which are specific to this method, some of which are relevant to other procedures such as fitting ring pessaries, and some of which are important for pelvic examinations in general. The opportunity to practise these skills under supervision consolidates learning and increases confidence. Doctors who feel confident fitting diaphragms are more likely to offer them as a contraceptive choice ${ }^{2}$ and therefore, despite the recent removal of the requirement to fit a diaphragm during DFFP training, the opportunity to do so offers important advantages.

Anecdotal evidence suggests that gaining practical experience of diaphragm-fitting during DFFP training is difficult. This difficulty arises from the scarcity of diaphragm users in clinics and the discomfort for trainer, patient and trainee which comes from exposing patients to unnecessary examination or examination by an inexperienced practitioner.

The difficulties related to teaching skills required for intimate examination have been addressed in the United States and Canada by employing professional patients. ${ }^{3-13}$ Professional patients have no medical qualification, but are trained to teach history taking and examination to doctors while role playing the part of the patient. A key feature of this educational method is the opportunity for the trainee to receive feedback from the 'patient'. Students trained in this way show improved communication and technical skills, and have recommended this method of training be continued. $^{4-9}$

Although $93 \%$ of medical schools in the United States and Canada employ professional patients to teach pelvic examination, ${ }^{14}$ none of the UK medical schools do so and there is 'little enthusiasm and some aversion' to this approach. ${ }^{15}$ The reasons for this difference remain unclear.

This study was undertaken to assess the feasibility of using professional patients to teach DFFP trainees to fit diaphragms. It aimed to answer the following research questions:

- Do instructing doctors/DFFP trainees experience practical difficulties in recruiting diaphragm users for training purposes in family planning clinics?

- What is the range of educational techniques currently used to teach the practical aspects of diaphragm fitting?

- Is the employment of professional patients for this purpose acceptable to instructing doctors and DFFP trainees?

- What should the curriculum for training professional patients for this purpose include?

- Is it possible to recruit and train professional patients for this purpose in the UK? These individuals are referred to as Family Planning Training Assistants (FPTAs) .

\section{Method}

Multiple data collection techniques were required to answer the research questions listed above, as outlined below.

1. Semi-structured interviews were completed with eight instructing doctors employed by the Department of Reproductive Health, Community Health South London NHS Trust. The interviews were tape recorded and partially transcribed. 
2. A questionnaire was distributed to all DFFP trainees attending a theoretical course organised by the South East London Family Planning Training Unit in July 1999 (40 trainees).

3. A postal questionnaire was sent to all doctors completing the practical element of their training between June 1999 and October 1999 (14 trainees).

4. The Delphi technique was used to achieve consensus on a training programme curriculum essential to enable professional patients to teach diaphragm fitting. ${ }^{16-21}$ This involved asking participants to answer a series of questionnaires in successive rounds to identify, clarify, refine and eventually reach consensus on the curriculum content and appropriate assessment methods. A total of 21 participants were invited to take part including two service users, two DFFP trainees, 12 family planning doctors and three nurses, one medical education specialist and one ethical adviser. They were asked what knowledge and skills they thought it would be important for an FPTA to acquire. The answers given by participants in round one formed the basis of the second questionnaire. This time participants were asked to rate each item on a scale of 1-5 (5 = absolutely essential; $1=$ not at all important). The results from the second questionnaire were analysed by calculating the mean and standard deviation for each. Any item with a mean greater than four was included in the curriculum and any item with a mean less than three was excluded. Any items on which consensus had not been reached were put forward to the third round. In this round participants had to decide whether the item was essential or non-essential, taking into account its mean and standard deviation. If the majority of participants thought the item was essential it was included.

5. Advertisements for those wishing to work as professional patients were placed in local family planning clinics, GP surgeries, college/University notice boards, and hospital and community health newsletters.

6. A training programme based on the curriculum defined by the Delphi technique was organised. Lectures, small group teaching, role playing and practical sessions with pelvic models were the teaching methods used to cover the curriculum. The curriculum included anatomy and physiology of the female reproductive tract, how a diaphragm is fitted, its mechanism of action and failure rate, what a woman needs to know to use a diaphragm, and how to give and receive feedback. Full details of the curriculum covered are given in the results section.

\section{Results}

The difficulty recruiting patients for training

All eight instructing doctors interviewed (100\% response rate) had experienced problems recruiting patients. This was especially difficult if the trainee was male, and most reported having trainees who had not fitted a diaphragm at the end of their eight sessions. Their solutions include advising female trainees to fit diaphragms on themselves or male trainees to fit them on their female partners, or asking GP registrars to recruit a patient from their practice. Three doctors have patients who attend the clinic specifically for training purposes, and some ask women being examined for another reason if they would agree to have a diaphragm fitted.

Of the 12 trainees completing their practical training who returned the questionnaire ( $86 \%$ response rate), half had had problems gaining practical experience of diaphragm fitting. Two did extra sessions to gain this experience, and two were asked to fit a diaphragm on themselves (one found this very uncomfortable). One trainee recruited an exdiaphragm user who was attending for a smear, but felt uncomfortable subjecting the patient to an unnecessary procedure, and for one trainee the instructing doctor arranged for a patient to come to the clinic specifically for training purposes.

\section{Inconsistencies in curriculum content and delivery}

When teaching diaphragm-fitting all eight instructing doctors explain the procedure to their trainee usually without a patient present, with four using a pelvic model to demonstrate the technique. Three instructing doctors fit the diaphragm first and then let the trainee examine the patient to assess the diaphragm position. The trainee then refits the diaphragm on the same patient. Five instructing doctors prefer to let the trainee fit the diaphragm without prior demonstration so that the patient is not unnecessarily subjected to two fittings. The size and position of the diaphragm is then checked. One instructing doctor sometimes fits the wrong size of diaphragm, or fits it incorrectly, and asks the trainee to identify the problem. Some doctors recruit the clinic nurse to help with theoretical teaching.

The DFFP trainees' reports of their teaching documented inconsistencies similar to those described above. In addition, it was notable that none had received feedback on their communication skills during the examination.

The acceptability of professional patients as trainers/ assessors

Five of the instructing doctors interviewed would be completely happy to delegate all diaphragm teaching to the FPTA and to jointly assess the trainee with her: 'I think the use of FPTAs will be an improvement on the current situation and the element of feedback will be invaluable for the trainee.'

Two of the instructing doctors would consider working with an FPTA only if the trainee had been unable to fit a diaphragm on a patient. Both these doctors were reluctant to hand over responsibility for assessment to the FPTA: 'It would be interesting to hear her opinions but if I'm to sign whether the trainee is competent or not I would want overall control'

One instructing doctor would be happy to work with FPTAs as patients but not as teachers.

The results of the questionnaire sent to DFFP trainees finishing their theoretical course are shown in Table 1. Of the 31 questionnaires returned by trainees doing the DFFP

Table 1 Results of questionnaire administered to DFFP trainees at the end of their theory course

\begin{tabular}{llll}
\hline & Yes & No & $\begin{array}{c}\text { Don't } \\
\text { know }\end{array}$ \\
\hline $\begin{array}{l}\text { Would you be happy being taught } \\
\text { by non-medical personnel? }\end{array}$ & $26(84 \%)$ & $1(3 \%)$ & $4(13 \%)$ \\
$\begin{array}{l}\text { Would you object to receiving } \\
\text { feedback from the FPTA on your } \\
\text { technical skills? }\end{array}$ & $2(7 \%)$ & $28(90 \%)$ & $1(3 \%)$ \\
$\begin{array}{l}\text { Would you object to receiving } \\
\text { feedback from the FPTA on your } \\
\text { communication skills? }\end{array}$ & $0(0 \%)$ & $26(84 \%)$ & $5(16 \%)$ \\
$\begin{array}{l}\text { Would you object to the FPTA } \\
\text { having input into your final } \\
\text { assessment? }\end{array}$ & $2(7 \%)$ & $23(74 \%)$ & $6(19 \%)$ \\
\hline
\end{tabular}


theoretical course (77.5\% response rate), $84 \%$ would be happy to be taught by non-medical personnel. Seven percent would object to receiving feedback from the FPTA on their technical skills and to input from the FPTA on their final assessment. None would object to receiving feedback from the FPTA on their communication skills. All those who objected being taught or assessed by FPTAs were practising GPs (unlike the majority of respondents who were GPs in training). In the free text section of the questionnaire the majority of comments were positive, for example: 'Good idea - willing clients are much better to learn on than reluctant ones.'

\section{The results of the Delphi technique}

Three rounds of the Delphi technique were required before consensus was reached. Response rates were $89 \%, 91 \%$ and $86 \%$, respectively. A broad but well-defined curriculum was developed on the basis of the results of the Delphi technique. It was also used to define teaching methods and assessment procedures. The results of the questions on knowledge and skills are shown in Table 2 and Table 3, respectively.

\section{Recruiting, training and assessing the FPTAs}

Five women were recruited onto the training programme. Three were students (studying postgraduate law, undergraduate anthropology and nursing), one had been working as a health care assistant in America, and one was a social science graduate. All were articulate and enthusiastic about the project. Only two were diaphragm users.

The training programme consisted of four sessions lasting 3 hours each. One candidate failed to complete the training programme because of family and work commitments. At the end of the course the FPTAs were assessed on their ability to teach diaphragm fitting to a trainee family planning nurse by an independent family planning instructing nurse, against a checklist of competencies. Three were found to be competent at their first assessment, and one needed further training and then passed.

\section{Discussion}

This study demonstrates the current lack of consistency in practical training for diaphragm fitting. Many of the strategies used to provide this training are inappropriate. Trainees' partners may feel coerced into participating and are unlikely to provide accurate feedback. The skills gained by female trainees fitting diaphragms on themselves are different to those required to fit a diaphragm on someone else. Trainees who practice the technique on patients in the clinic impose an unnecessary examination, often imperfectly performed on the patient, and the trainees' consequent embarrassment inhibits learning. These strategies provide little opportunity for constructive feedback, particularly on communication

Table 2 Results from rounds 1, 2 and 3 of the Delphi technique: Question One. What knowledge do you think it would be important for the FPTAs to acquire?

\begin{tabular}{|c|c|c|c|c|c|}
\hline \multirow{2}{*}{\multicolumn{2}{|c|}{ Items generated in round one }} & \multicolumn{2}{|c|}{ Results from round 2} & \multirow[t]{2}{*}{ No. of votes in round 3} & \multirow[t]{2}{*}{ Outcome } \\
\hline & & Mean & $\mathrm{SD}$ & & \\
\hline a) & Basic physiology of female reproductive tract & 3.26 & 1.15 & 12 & included \\
\hline b) & Basic anatomy of female reproductive tract & 4.63 & 0.60 & N/A & included \\
\hline c) & Menstrual cycle & 3.53 & 1.02 & 11 & included \\
\hline d) & Assess correct size of diaphragm & 4.74 & 0.56 & N/A & included \\
\hline e) & Application of spermicide & 4.89 & 0.32 & N/A & included \\
\hline f) & Interactions of diaphragms with other substances & 4.53 & 0.77 & N/A & included \\
\hline g) & The level DFFP trainees are in their training & 2.63 & 1.07 & N/A & excluded \\
\hline h) & Failure rates of diaphragms and reasons & 4.68 & 0.58 & N/A & included \\
\hline i) & Other methods of contraception & 2.53 & 0.96 & N/A & excluded \\
\hline j) & Sexually transmitted infections & 3.11 & 1.15 & 7 & excluded \\
\hline $\mathrm{k})$ & Mechanism of action of diaphragm & 4.63 & 0.50 & N/A & included \\
\hline 1) & Information that women users need & 4.84 & 0.40 & N/A & included \\
\hline m) & When refitting of diaphragms required & 4.58 & 0.80 & N/A & included \\
\hline n) & Problems diaphragms may cause & 4.42 & 0.84 & N/A & included \\
\hline o) & Sexual taboos in society & 2.47 & 1.02 & N/A & excluded \\
\hline p) & Ethics/law/consent & 2.79 & 1.13 & N/A & excluded \\
\hline
\end{tabular}

N/A = not applicable

Note: See point 4 under methodology

Table 3 Results from rounds 1, 2 and 3 of the Delphi technique: Question Two. What skills do you think it would be important for the FPTAs to acquire?

\begin{tabular}{|c|c|c|c|c|c|}
\hline \multirow{2}{*}{\multicolumn{2}{|c|}{ Items generated in round one }} & \multicolumn{2}{|c|}{ Results from round 2} & \multirow[t]{2}{*}{ No. of votes in round 3} & \multirow[t]{2}{*}{ Outcome } \\
\hline & & Mean & $\mathrm{SD}$ & & \\
\hline a) & Communication skills & 4.89 & 0.32 & $\mathrm{~N} / \mathrm{A}$ & included \\
\hline b) & Ability to locate cervix & 4.89 & 0.32 & N/A & included \\
\hline c) & Ability to provide feedback & 4.79 & 0.54 & N/A & included \\
\hline d) & Ability to ensure diaphragm fitted correctly & 4.74 & 0.65 & $\mathrm{~N} / \mathrm{A}$ & included \\
\hline e) & Ability to fit diaphragm on self & 4.58 & 0.96 & N/A & included \\
\hline f) & Ability to fit diaphragm on others & 4.37 & 1.16 & N/A & included \\
\hline g) & Ability to fit variety of diaphragms & 3.68 & 1.49 & 17 & included \\
\hline h) & Psychosexual knowledge & 2.74 & 0.65 & N/A & excluded \\
\hline i) & Manual dexterity & 2.63 & 0.90 & N/A & excluded \\
\hline j) & Interpersonal skills & 4.53 & 0.51 & N/A & included \\
\hline $\mathrm{k})$ & Able to recognise incorrectly fitted diaphragm & 4.84 & 0.50 & N/A & included \\
\hline 1) & Reflects on experience of being examined & 4.37 & 0.50 & N/A & included \\
\hline $\mathrm{m})$ & Pretends ignorance when being examined & 3.58 & 1.17 & 5 & excluded \\
\hline
\end{tabular}


during intimate examination. The majority of instructing doctors and DFFP trainees in this study would welcome a new approach to teaching the practical elements of diaphragm fitting, and welcome the possibility of recruiting and training laywomen to work as professional patients for this purpose.

The effectiveness of the professional patient in teaching communication skills during intimate examinations ${ }^{6-8}$ raises questions about their potential employment to assess these skills among those training for the DFFP (possibly at the first session) so that additional training can be offered to those candidates who require it. The apparent feasibility of training and recruiting professional patients in the UK also raises questions about their possible employment in undergraduate training and the post-graduate training of general practitioners and obstetrician/gynaecologists. Their employment is consistent with recent BMA guidelines on involving patients in quality improvement activities ${ }^{22}$ and they could help doctors to update and maintain their examinations skills as part of their continuing medical education.

A further research project is now underway which aims to compare the effectiveness of FPTAs as trainers in comparison with instructing doctors.

\section{Funding and competing interests}

Funding. This research was funded by the Special Trustees of Guys and St Thomas' Hospitals

Competing interests: None declared.
References

Guillebaud J. Contraception your questions answered Third Edition. London: Churchill Livingstone, 1999

Beyond Acceptability: Users' Perspectives on Contraception. London: Reproductive Health Matters for the World Health Organisation. 1997 23-35

Livingstone RA, Ostrow DN. Professional patient-instructors in the teaching of the pelvic examination. Am J Obstet Gynecol 1978; 132 (1): 64-67.

Holzman GB, Singleton D, Holmes TF, et al. Initial pelvic examination instruction: The effectiveness of three contemporary approaches. Am J Obstet Gynecol 1977; 129 (2):124-129.

5 Kleinman DE, Hage ML, Hoole AJ, et al. Pelvic examination instruction and experience: a comparison of laywoman-trained and physician-trained students. Acad Med 1996; 71 (11) 1239-243.

6 Guenther SM, Laube DW, Matthes S. Effectiveness of the Gynecology Teaching Associate in Teaching Pelvic Examination Skills. J Med Education 1983; 58 (1): 67-69.

Livingstone RA, Moodie PF, Ostrow DN. A Follow-up Study of Patient- Instructors Who Teach the Pelvic Examination. J Med Education 1980; 55 (8): 715-717.

8 Shain RN, Crouch SH, Weinberg PC. Evaluation of the Gynecology Teaching Associate Versus Pelvic Model Approach to Teaching Pelvic Examination. J Med Education 1982; 57 (8): 646-648.

Kretzschmar RUM. Evolution of the Gynecology Teaching Associate: An education specialist. Am J Obstet Gynecol 1978; 131(4): 367-373.

10 Godkins TRY, Duffy D, Greenwood J, et al. Utilization of Simulated Patients To Teach The "Routine" Pelvic Examination. J Med Education 1974; 49 (12): 1174-178.

1 Johnson GH, Brown TC, Stenchever MA, et al. Teaching pelvic examination to second yea medical students using programmed patients. Am J Obstet Gynecol 1975; 121 (5): 714-717.

12 Rochelson BL, Baker DA, Mann WJ, et al. Use of Male and Female Professional Patient Teams in Teaching Physical Examination of the Genitalia. J Reprod Med 1985; 30 (11) $864-866$

13 Tolmas HC. Adolescent Pelvic Examination. An Effective Practical Approach. Am J Dis Child 1991; 145 (11): 1269-271.

4 Beckmann CR, Spellacy WN, Yank A, et al. Initial instruction in the pelvic examination in U.S. and Canada 1983. Am J Obstet and Gynecol 1985; 151 (1): 58-60.

Biggs JS, Harden RM, Howie P. Undergraduate Obstetrics and Gynaecology in the United Kingdom and the Republic of Ireland, 1989. Br J Obstet Gynaecol 1991; 98 (2): 127-134.

Stritter FT, Tresolini CP, Reeb KG. The Delphi Technique in Curriculum Development. Teaching and Learning in Medicine; 6 (2): 136-141.

17 Stewart J, O'Halloran C, Harrigan P, et al. Identifying Appropriate Tasks for the pre registration year: modified Delphi technique. BMJ 1999; 319: 224-229.

registration year: modified Delphi technique. BMJ 1999; 319: 224-229.
Williams PL, Webb C. The Delphi technique: a methodological discussion. Journal of Williams PL, Webb C. The Delphi
Advanced Nursing 1994; 19: 180-186.

9 Duffield C. The Delphi Technique. Journal of Advanced Nursing 1989; 6 (2): 41-45.

20 Jones J, Hunter D. Consensus methods for medical and health services research. BMJ 1995 311: $376-380$.

1 Crotty M. The emerging role of the British nurse teacher in Project 2000 programmes: a Delph survey. Journal of Advanced Nursing 1993; 18: 150-157.

22 British Medical Association. Involving patients in quality improvement activities: An introduction for clinicians. London: BMA, 2000. 